Hartmann, H.T. and D.E. Kester. 1975. Plant propagation, principles and practices. 3 rd ed Prentice-Hall, Englewood Cliffs, N.J.

Milbocker, D.C. 1983. Ventilated high humidity propagation. Combined Proc. Intl. Plant Prop. Soc. 33:384-387.

Milbocker, D.C. and R. Wilson. 1979. Temperature control during high humidity propagation.
J. Amer. Soc. Hort. Sci. 104:123-126.

Miller, J.D. 1978. Design and the desert environment. Univ. Ariz., Office Arid Lands Studies, Arid Lands Resource Info. Paper 13.

Neter, J., W. Wasserman, and M.H. Kutner. 1983. Applied linear regression models. Irwin, Homewood, 111.

Nokes, J. 1986. How to grow native plants of
Texas and the southwest. Texas Monthly Press, Austin.

Thomas, C.C. 1936. The propagation of some deciduous trees from softwood cuttings. Natl. Hort. Msg. 15:103-107.

Tracz, T. 1983. In: Alexander, J. and G. Keller (moderators). New plant forum.Comb. Proc. Intl. Plant Prop. Soc. 33:489-490.

\title{
Shoot Length Control of Tree Peony (Paeonia suffruticosa) with Uniconazole and Paclobutrazol
}

\author{
Morihiko Hamada, Takashi Hosoki, and Toshiyuki Maeda \\ Laboratory of Vegetable and Ornamental Horticulture, Faculty of \\ Agriculture, Shimane University, Nishikawatsu-cho 1060, Matsue 690, \\ Japan
}

Additional index words. growth retardant, triazol compounds, flower forcing

\begin{abstract}
Potted plants of 'Taiyoh' and 'Hanakisoi' tree peony (Paeonia suffruticosa Andr.) were treated with a foliar spray of uniconazole or paclobutrazol for shoot length control. Uniconazole sprays at 25 or $50 \mathrm{ppm}$ upon sprouting effectively reduced shoot length in both cultivars. The retarding effect was greater in 'Taiyoh' than in 'Hanakisoi' at $25 \mathrm{ppm}$. Uniconazole treatment did not influence flower diameter or days to flowering in either cultivar. Paclobutrazol sprays at 500 and $1000 \mathrm{ppm}$ were less effective in reducing 'Hanakisoi' shoot length than uniconazole sprays at 25 and $50 \mathrm{ppm}$. Chemical names used: E-1-(4-chlorophenyl)-4,4-dimethyl-2-(1,2,4-triazol-l-yl)-l-pentan-3-ol (uniconazole); (1RS, 3RS )-1-1-(4-chlorophenyl)-4,4-dimethyl-2-(1,2,4-triazol-l-yl) -lpentan-3-ol (paclobutrazol).
\end{abstract}

Tree peonies have long been cultivated as garden landscape plants in the United States, Europe, and Japan (Gratwick, 1979; Everett, 1981). Nearly 2 million plants are' produced in Japan every year and $>10 \%$ are shipped to the United States (Hosoki, 1985). While demand for garden plants decreased in the past 10 years, consumers are purchasing more potted plants or cut flowers (Hosoki, 1985). Some tree peony growers are concentrating on forcing potted plants or cut flowers (Hosoki et al., 1984) because of the high market price ( $\$ 10$ to $\$ 20$ per pot plant compared to $\$ 3$ to $\$ 4$ per nursery plant). Tree peony is propagated by grafting onto the herbaceous peony (Paeonia lactiflora Pall.) and grown for at least 2 years (Reath, 1979; Everett, 1981). The plants bloom in the spring on 3year-old shoots. Apical dominance of tree peony is strong, since a solitary flower is formed without branching on the top of the current shoot (Everett, 1981). A major problem in pot flower production is control of excessive shoot growth. In previous experiments we conducted for 6 years, common growth retardants, such as daminozide, chlormequat, and ancymidol, did not retard

Received for publication 1 May 1989. The cost of publishing this paper was defrayed in part by the payment of page charges. Under postal regulations, this paper therefore must be hereby marked advertisement solely to indicate this fact. shoot growth of tree peony at all or retarded it only by $18 \%$ at best. This was inadequate for commercial use.

New triazol growth retardants, such as paclobutrazol (Wilfret, 1981) or uniconazole (Ooshio et al., 1981), were investigated. Paclobutrazol has been shown to retard shoot growth of pot plants, such as Camellia hybrids, chrysanthemum, and zinnia (Wilkinson and Richards, 1988; Sanderson et al., 1988; Cox and Keever, 1988). Uniconazole $\left(\mathrm{C}_{15} \mathrm{H}_{18} \mathrm{CIN}_{3} \mathrm{O}\right)$, with a similar chemical formula to paclobutrazol $\left(\mathrm{C}_{15} \mathrm{H}_{20} \mathrm{ClN}_{3} \mathrm{O}\right)$, has been used for control of plant height in $\mathrm{Ca}$ mellia, Rhododendron, and azalea (Kiyosawa and Hirata, 1986; Kunishige et al., 1985; Shinozaki et al., 1987). In Camellia, uniconazole strongly reduced shoot growth; 50\% to $55 \%$ height reduction with a spray application at 25 or $50 \mathrm{ppm}$ when compared with the control. In Rhododendron and azalea, the reduction of shoot length was $20 \%$ to $37 \%$. In rice seedling tests, uniconazole strongly retarded shoots when compared with paclobutrazol (Takeuchi et al., 1987).

The objective of the present study was to investigate the control of shoot length of tree peony using paclobutrazol and uniconazole.

All the experiments were conducted from March to April, when flower forcing is most frequently practiced among tree peony growers. A popular pink cultivar Hanakisoi (Floral Rivalry), grown at the Shimane Univ. field, was used to test paclobutrazol. Plants were lifted and potted into plastic containers ( $24 \mathrm{~cm}$ in diameter, 4.5 liters) containing a sandy-soil medium mixed with $30 \%$ bark. Plants were then grown in a glasshouse where temperature set points were $\approx 22$ to $27 \mathrm{C}$ /day and 15 to $18 \mathrm{C} /$ night. Plants were watered almost every day.

For the paclobutrazol treatment, 500 and $1000 \mathrm{ppm}$ aqueous solutions including $0.1 \%$ surfactant (Tween-20) were sprayed on the foliage three times, beginning when the budded sprouts were $3 \mathrm{~cm}$ long. Control plants were sprayed only with water including $0.1 \%$ surfactant, The second and third sprays were applied 5 and 10 days after the first treatment. Seven replicates were used for each treatment. For the uniconazole treatment, a red cultivar Taiyoh (Sun) and 'Hanakisoi' were used. Twenty-five and $50 \mathrm{ppm}$ aqueous solutions, including the surfactant, were sprayed on the foliage twice at a 5-day interval; the first spray when the sprout was 3 $\mathrm{cm}$ long. Seven and five replicates were used for 'Taiyoh' and 'Hanakisoi', respectively. For both chemical treatments, shoot length at flowering, flowering rate, days to flowering after treatment, flower diameter, and phytotoxic injury to the leaves were recorded.

At flowering time, paclobutrazol treatment on 'Hanakisoi' reduced shoot length only by $18 \%$ with $500 \mathrm{ppm}$ and by $17 \%$ with $1000 \mathrm{ppm}$ when compared with the shoot length $(22 \mathrm{~cm})$ of the control. Flowering was not delayed by paclobutrazol treatments compared with those of the control. Flower diameter was not affected by the treatments $(13.3 \mathrm{~cm}$ at $500 \mathrm{ppm}, 13.3 \mathrm{~cm}$ at $1000 \mathrm{ppm}$, and $12.0 \mathrm{~cm}$ for the control). Leaf tips of plants treated at $1000 \mathrm{ppm}$ were wrinkled. Plant root immersion into 200 or 400 ppm aqueous solution for up to $36 \mathrm{hr}$ before plant-

Table 1. Effect of uniconazole on shoot length of 'Taiyoh' and 'Hanakisoi' tree peony.

\begin{tabular}{lcc}
\hline \hline Cultivar & $\begin{array}{c}\text { Foliar-spray } \\
\text { concn } \\
(\mathrm{ppm})\end{array}$ & $\begin{array}{c}\text { Shoot } \\
\text { length } \\
(\mathrm{cm})\end{array}$ \\
\hline Taiyoh & 0 & 25.2 \\
& 25 & 17.8 \\
Linear & 50 & 15.2 \\
& & $2 \%$ \\
Hanakisoi & 0 & 16.2 \\
& 25 & 12.2 \\
Linear & 50 & $*$
\end{tabular}

$\sqrt{\mathrm{S}, * \text { Nonsignificant or significant at } P=0.05 \text {, re- }}$ spectively. 

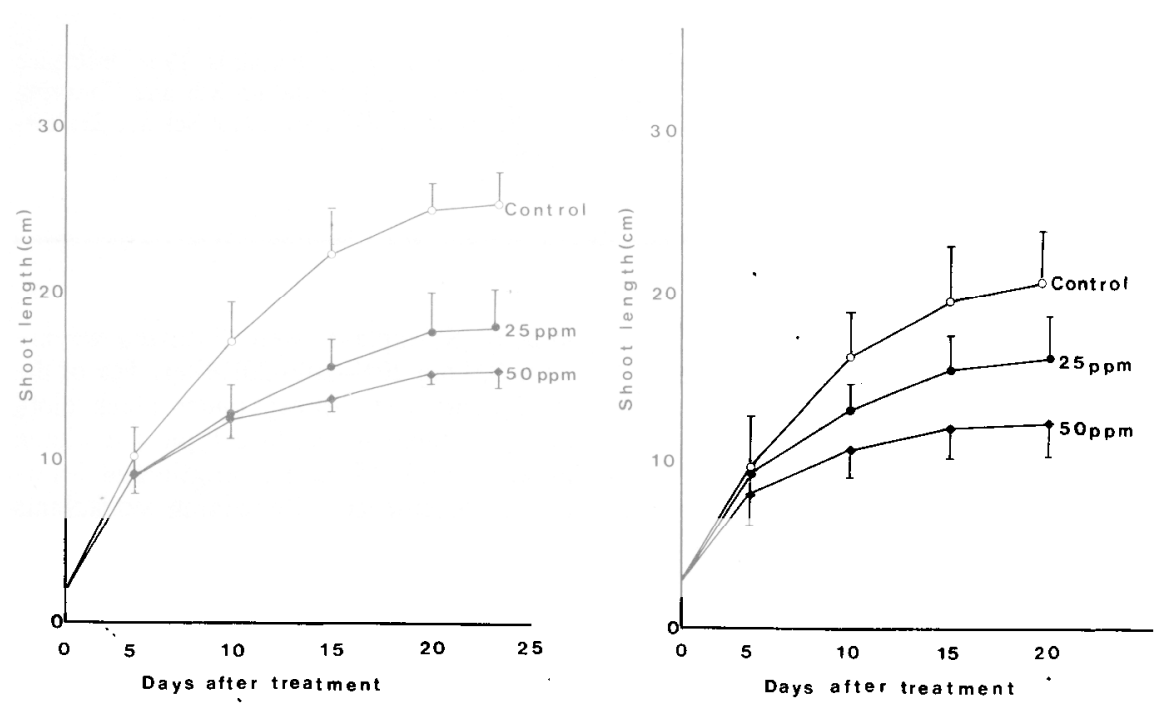

Fig. 1. Shoot growth of 'Taiyoh' (left) and 'Hanakisoi' (right) after foliar sprays of uniconazole at 0,25 , or $50 \mathrm{ppm}$. The first spray and second spray were conducted at 0 and 5 days, respectively. Vertical bars indicate so.

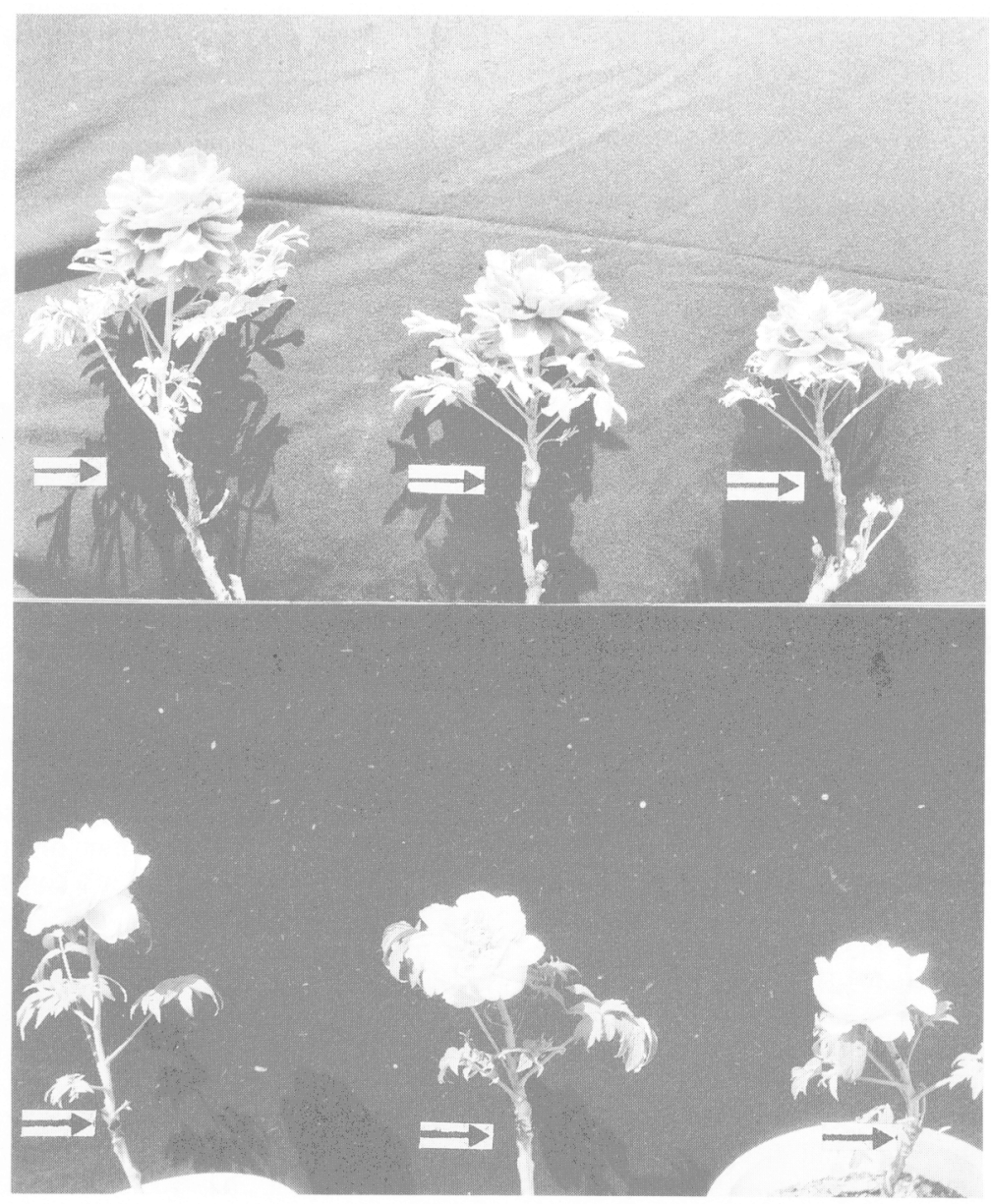

Fig. 2. Shoot length at flowering time with uniconazole treatment: 'Taiyoh' (upper), 'Hanakisoi' (lower). Control (left), $25 \mathrm{ppm}$ (middle), $50 \mathrm{ppm}$ (right). Arrow indicates the base of the current shoots.

ing did not reduce shoot growth at all (data not shown), probably because large tuberous graft-roots of herbaceous peony diluted the effect of the chemical or inhibited its upward movement.

For uniconazole treatment on 'Taiyoh', shoots at flowering were $29 \%$ shorter at 25 was between 14 and $15 \mathrm{~cm}$ for 'Taiyoh' and between 11 and $12 \mathrm{~cm}$ for 'Hanakisoi'; the corresponding values for days to flowering were 23 or 24 and 19 or 20 . Treatment with the $50 \mathrm{ppm}$ spray induced slight leaf-tip wrinkling, although it did not seriously detract from the appearance. Similar results were obtained for 'Hanakisoi', where shoot length was reduced by $23 \%$ with a 25 ppm spray and $41 \%$ with 50 ppm compared with the shoot length of the control $(21.0 \mathrm{~cm})$ (Figs. 1 and 2). Phytotoxic injury was not observed in 'Hanakisoi', even at the 50-ppm treatment.

In a bioassay using rice seedling (Takeuchi et al., 1987), shoot growth retardation by uniconazole was 100 times as strong as that of paclobutrazol at equivalent molecular concentrations. In our study on tree peony, uniconazole also was more effective at low concentrations than paclobutrazol, Paclobutrazol treatment was phytotoxic at $1000 \mathrm{ppm}$, where the retardation effect on shoot growth was inadequate.

Uniconazole treatment at $25 \mathrm{ppm}$ was slightly less effective on 'Hanakisoi' than on 'Taiyoh'. Cultivar differences have been reported in potted chrysanthemum and azalea (Oosio et al., 1981; Shinozaki et al., 1987).

In conclusion, two uniconazole foliar sprays applied at budbreak retarded shoot growth of tree peony. This would be a valuable commercial practice to obtain a pleasing aesthetic balance in pot plants.

\section{Literature Cited}

Cox, D.A. and G.J. Keever. 1988. Paclobutrazol inhibits growth of zinnia and geranium. HortScience 23:1029-1030.

Everett, T.H. 1981. The New York botanical garden illustrated encyclopedia of horticulture. vol. 7. Garland, New York.

Gratwick, W. 1979. Tree peonies, p. 51-52. In: G.M. Kessenich (ed.). The best of 75 years. Amer. Peony Soc., Minnesota.

Hosoki, T. 1985. Tree peony production of Shimane pref., Japan. Amer. Peony Sot. But. 253:24-26.

Hosoki, T., M. Hamada, and K. Inaba. 1984. Forcing of tree peony for December shipping by pre-chilling and chemical treatments. J. Jpn. Soc. Hort. Sci. 53:187-193.

Kiyosawa, Y. and Y. Hirata. 1986. Test of growthretarding effect of S-07 on Camellia (in Japanese). Veg. and Ornamental Crops Res. Sta., Kurume Branch Bul. 10:187-188.

Kunishige, M., K. Nishio, and K. Sudo. 1985. Growth-retarding effect of uniconazol on Rhododendron (in Japanese). Jpn. Soc. Hort. Sci. Spring Meeting. 1985:324-325. (Abstr.)

Ooshio, H., K. Izumi, S. Hashimoto, Y. Funaki, and K. Tanaka. 1981. Effect of a new growth retardant, S-07 (in Japanese). Jpn. Soc. Hort. Sci. Spring Meeting. 1981:412-413. (Abstr.)

Reath, D. 1979. Root-grafting of tree peonies, $p$. 61-62. In: G.M. Kessenich (ed.). The best of 75 years. Amer. Peony Sot., Minnesota.

Sanderson, K. C., W.C. Martin, Jr., and. J. McGuire. 1988. Comparison of paclobutrazol tablets, drenches, gels, capsules, and sprays on chrysanthemum growth. HortScience 23: 1008 1009.

Shinozaki, M., T. Horiguch, and K. Itami. 1987. Growth-retarding effect of chemical retardant on azalea and Rhododendron (in Japanese). Or- 
namentals and Landscape Plants Expt. Ctr. Saitama Pref. Annu. Rpt. p. 49-51.

Takeuchi, Y., M. Konnai, and T. Takematsu. 1987.

Bioassay methods of growth retardants (in Jap- anese). Reg. of Plants 22:130-141.

Wilfret, G.J. 1981. Height retardation of poinsettia with ICI-PP-333. HortScience 16:443. (Abstr.)
Wilkinson, R.I. and D. Richards. 1988. Influence of paclobutrazol on the growth and flowering of Camellia $\times$ Williamsii. HortScience 23:359360 .

\title{
Rooting Softwood Cuttings of Acer griseum: Promotion by Stockplant Etiolation, Inhibition by Catechol
}

\author{
Brian K. Maynard and Nina L. Bassuk \\ Department of Floriculture and Ornamental Horticulture, Cornell \\ University, Ithaca, IVY 14853
}

Additional index words. adventitious root formation, auxin, banding, light, paperbark maple, phenolics, propagation

\begin{abstract}
Effects of stockplant etiolation, stem banding, exogenous auxin, and catechol on the rooting response of softwood cuttings of paperbark maple (Acer griseum Pax.) were studied. Etiolated cuttings rooted better than light-grown cuttings, while stem banding did not affect rooting percentage (light-grown, 10\%; light-grown + banding, $18 \%$; etiolated, $41 \%$; etiolated + banding, 37\%). IBA did not promote, but catechol inhibited rooting (control, 31\%; IBA, 37\%; catechol, 17\%; IBA + catechol, $21 \%$ ). Root number was increased by IBA and unaffected by catechol. The distance from the cutting base to the first emerged root was measured as an indication of auxin toxicity. IBA interacted with etiolation and stem banding to increase this distance, which was greater in catechol-treated cuttings. Chemical names used: 1,2-benzenedio1 (catechol); 1H-indole-3-butanoic acid (IBA).
\end{abstract}

Paperbark maple is a desirable ornamental trees species that has presented a challenge to plant propagators for many years. Seed germination is normally poor (Fordham, 1969), grafting success is limited, and cuttings are generally considered difficult to root (Dirr and Heuser, 1987). However, several studies have reported some success with softwood cutting propagation of seedling material (Dirr and Heuser, 1987, p. 83). Of special interest is a study by Ming and Meyer (1983) in which cuttings from 2-year-old seedlings were soaked for $24 \mathrm{hr}$ in $1 \mathrm{H}$-indole-3 acetic acid (IAA) and the phenolic compound catechol. Up to $100 \%$ rooting was obtained after a 24-hr pre-sticking soak in a $2 \%$ aqueous ethanol $(\mathrm{EtOH})$ solution of 1.1 $\times 10^{-3} \mathrm{M}$ IAA plus $4.5 \times 10^{-3} \mathrm{M}$ catechol (193 and $495 \mathrm{mg} \cdot$ liter $^{-1}$, respectively). Their study suggested that catechol might have acted as rooting cofactor which, in conjunction with exogenous IAA, promoted rooting of several difficult-to-root maple species.

Stockplant etiolation and stem banding with Velcro have been used to stimulate rooting of softwood cuttings from both young (1year-old seedling) and mature (30-year-old specimen) stockplants of Acer griseum (Maynard and Bassuk, 1987). Though im-

Received for publication 27 Feb. 1989. The cost of publishing this paper was defrayed in part by the payment of page charges. Under postal regulations, this paper therefore must be hereby marked advertisement solely to indicate this fact. provements in rooting response were demonstrated, the best rooting percentages observed were markedly lower than those of Kling and Meyer (34\% vs. $100 \%$ ).

The objective of the present study was to investigate a combination of the methods used in the studies described above, specifically, the influences of etiolation and exogenously applied auxin and catechol on adventitious root formation in cuttings. The study was designed as a $2 \times \mathbf{2} \times \mathbf{2} \times 2$ factorial to test the effects of stockplant etiolation, Velcro-banding with IBA, and auxin or catechol soaks on the rooting of softwood basal stem cuttings of $A$. griseum. This study was undertaken to incorporate certain aspects of the work of Kling and Meyer (1983), not to replicate their study. Based on the assumption that IAA is more readily degraded than IBA in the course of a 24-hr soak (Dirr and Heuser, 1987, p. 37), we chose to substitute IBA for IAA.

Twenty 5-year-old field-grown seedling stockplants of A. griseum (Schichtel's Nursery, Orchard Park, N. Y.; provenance unknown) were potted into 2-liter plastic containers in a medium of 1 sandy loam soil: 1 sphagnum peatmoss: 1 perlite (by volume) and placed in cold storage at 5C for 8 weeks. On 1 Dec. 1987, all plants were placed in a greenhouse maintained at an average day/ night temperature of $20 \mathrm{C}$. Incandescent lamps $(100 \mathrm{~W})$, suspended $\approx 3 \mathrm{~m}$ above the stockplants and spaced $1 \mathrm{~m}$ apart, were used from 4:00 PM to 12:00 PM to extend the natural photoperiod to $\approx 16 \mathrm{hr}$ (irradiance not deter- mined). Stockplants were fertilized weekly with $200 \mathrm{mg} 20 \mathrm{~N}-10 \mathrm{P}-20 \mathrm{~K} / \mathrm{liter}$. Ten of the stockplants were forced under black cloth (>98\% shade) to produce typical etiolated growth (lack of color, lengthened internodes, succulence). Remaining stockplants were grown without shade. Two weeks later, shoots from one-half of the light-grown and etiolated plants were basally banded using 2.5-cm wide strips of Velcro coated with $0.8 \%$ IBA in talc, the standard procedure for stem banding developed by Maynard and Bassuk (1987). Etiolated plants were then acclimated to full sunlight over 4 days by first removing the cover on the north side, and then gradually rolling the cloth back each day until all 10 plants were in full sun. Basal shoot cuttings were taken 4 weeks later from positions throughout the stockplant crown and cut to a length of 7 to $10 \mathrm{~cm}$ with one pair of leaves. The terminal growth was removed. Banded shoots were cut immediately proximal to the Velcro bands and the bands removed. Four types of softwood cuttings were taken: 1) light-grown, nonbanded shoots (controls); 2) light-grown, banded shoots (banded); 3) etiolated shoots that had greened for 4 weeks (etiolated); and 4) etiolated and banded shoots, which yielded a cutting with an etiolated base (etiolated and banded).

All the cuttings were wounded along one side $(=2 \mathrm{~cm})$ by scraping to remove the bark, and the basal $1 \mathrm{~cm}$ of each cutting was soaked for $24 \mathrm{hr}$ at room temperature in one of four solutions containing 2\% ethanol: $2 \%$ ethanol only (control); $4.9 \times 10^{-4} \mathrm{M}$ IBA $(100$ $\mathrm{mg} \cdot$ liter $\left.^{-1}\right) ; 9.1 \times 10^{-4} \mathrm{M}$ catechol (100 $\mathrm{mg} \cdot$ liter $\left.^{-1}\right)$; or $4.9 \times 10-^{4} \mathrm{M} \mathrm{IBA}$ and 9.1 $\times 10-{ }^{4} \mathrm{M}$ catechol. Cuttings of each treatment were then distributed randomly into five groups of six cuttings each before insertion to a depth of $\approx 1 \mathrm{~cm}$ in a medium of 2 perlite :1 sphagnum peatmoss (v/v) in a completely randomized design. Rooting took place under mist (6 sec every 4 min from 6:00 AM to $8: 30 \mathrm{PM})$, with bottom heat $(25 \mathrm{C})$, and a 16-hr photoperiod (see above) provided by $100 \mathrm{~W}$ incandescent lamps suspended $1 \mathrm{~m}$ above the medium and spaced $1 \mathrm{~m}$ apart. Cuttings were evaluated for rooting after 38 days. Cuttings were considered rooted if they possessed one or more roots $>1 \mathrm{~mm}$ long. Rooting percentage, the number of roots per rooted cutting, and the distance from the cutting base to the first emerged root were recorded. Data were analyzed using the PROC GLM option of SAS (SAS Institute, 1985); percentage data were transformed to arcsin square root before analysis (Snedecor and Cochran, 1980).

An analysis of variance (Table 1) shows main effects and interactions among treatments. All third- and fourth-order interactions were nonsignificant and were pooled in 